\title{
TIMP-1 Induces $\alpha$-Smooth Muscle Actin in Fibroblasts to Promote Urethral Scar Formation
}

\author{
Yinglong Sa ${ }^{a}$ Chao $\mathrm{Li}^{\mathrm{a}}$ Hongbin $\mathrm{Li}^{\mathrm{a}}$ Hailin Guo \\ aDepartment of Urology, Shanghai Sixth People's Hospital, Shanghai Jiaotong University, Shanghai, \\ China
}

\section{Key Words}

Tissue inhibitor of metalloproteinases-1 (TIMP-1) - $\alpha$-smooth muscle actin ( $\alpha$-SMA) - Transforming growth factor $\beta 1$ (TGF $\beta 1)$ - Epithelial-mesenchymal transition (EMT) • Urethral scar

\begin{abstract}
Background/Aims: Tissue inhibitor of metalloproteinases-1 (TIMP-1) has been reported to upregulate in urethral scar. However, the underlying molecular mechanisms remain undefined. Methods: Here, we studied levels of TIMP-1 and $\alpha$-smooth muscle actin ( $\alpha$-SMA) in the fibroblasts isolated from urethral scar tissues, compared to the fibroblasts isolated from normal urethra. Then we either overexpressed TIMP-1, or inhibited TIMP-1 by lentiviruses carrying a transgene or a short hairpin small interfering RNA for TIMP-1 in human fibroblasts. We examined the effects of modulation of TIMP-1 on $\alpha-S M A$, and on epithelial-mesenchymal transition (EMT)-related genes. We also studied the underlying mechanisms. Results: We detected significantly higher levels of TIMP-1 and $\alpha$-smooth muscle actin ( $\alpha$-SMA) in the fibroblasts isolated from urethral scar tissues, compared to the fibroblasts isolated from normal urethra. Moreover, the levels of TIMP-1 and $\alpha$-SMA strongly correlated. Moreover, we found that TIMP-1 significantly increased levels of $\alpha$-SMA, transforming growth factor $\beta 1$ (TGF $\beta 1$ ), Collagen I and some other key factors related to an enhanced EMT, suggesting that TIMP-1 may induce transformation of fibroblasts into myofibroblasts to promote tissue EMT to enhance the formation of urethral scar. Moreover, increases in TIMP-1 also induced an increase in fibroblast cell growth and cell invasion, in an ERK/MAPK-signalingdependent manner. Conclusion: Our study thus highlights a pivotal role of TIMP-1 in urethral scar formation.
\end{abstract}

Yinglong Sa

KARGER 125
Department of Urology, Shanghai Sixth People's Hospital, Shanghai Jiaotong University, 600 Yishan Road, Shanghai 200233 (China)

Tel. +8618930177669, Fax +862164369181, E-Mail yinglong_sa@163.com 


\section{Introduction}

Urethral stricture is a fibrotic process in incompliant scarred tissue, resulting in constricted urethral lumen [1-4]. The common causes for developing urethral stricture are indirect or direct trauma-like side effects, such as surgical correction of urinary incontinence [1-4]. Although urethrotomy under direct vision could be an effective therapy for minor urethral stricture in the penile segment, the recurrence rate is pretty high [1-4]. Scar tissue for larger strictures is usually treated with excision by anastomotic urethroplasty, free buccal mucosal transplants or foreskin pedicled grafts [1-4].

The molecular basis of urethral stricture involves activation of tissue fibroblasts, their transformation into myofibroblasts, following outgrowth and increased deposition of collagens, and consequent changes in extracellular matrix components [5-8]. The matrix metalloproteinase (MMP) family members are involved in the breakdown of extracellular matrix during embryonic development, tissue remodeling and disease processes [9-13].

Tissue inhibitor of metalloproteinases 1 (TIMP-1) is a glycoprotein ubiquitously expressed in various human cells and tissues [14-16]. TIMP-1 controls the activity of MMPs and appears to an important regulator of extracellular matrix turnover [14-16]. Moreover, TIMP-1 also regulates cellular processes including cell growth, apoptosis, and differentiation that are independent of its metalloproteinase inhibitory activity [14-16]. Recently, TIMP-1 has been reported to upregluate in urethral scar tissues, which has been suggested to be responsible for decreased collagenase activities [17-20]. However, little is known about the effects of TIMP-1 on fibroblasts and the exact downstream mechanisms of TIMP-1-mediated cell signaling.

Here, we found significantly higher levels of TIMP- 1 and $\alpha$-smooth muscle actin ( $\alpha$-SMA) in the fibroblasts isolated from urethral scar tissues, compared to the fibroblasts isolated from normal urethra. Moreover, the levels of TIMP-1 and $\alpha$-SMA strongly correlated. Then we either overexpressed TIMP-1, or inhibited TIMP-1 by lentiviruses carrying a transgene or a short hairpin small interfering RNA for TIMP-1 in human fibroblasts. We found that TIMP1 significantly increased levels of $\alpha$-SMA, transforming growth factor $\beta 1$ (TGF $\beta 1$ ), Collagen I and some other key factors related to an enhanced epithelial-mesenchymal transition (EMT), suggesting that TIMP-1 may induce transformation of fibroblasts into myofibroblasts to promote tissue EMT to enhance the formation of urethral scar. Moreover, increases in TIMP-1 also induced an increase in fibroblast cell growth and cell invasion, in an ERK/MAPKsignaling-dependent manner.

\section{Materials and Methods}

Patient tissue specimens

A total of 21 resected urethral scar tissue specimens from patients were collected for this study. The normal urethral tissues from the same patient were used as controls. All specimens had been histologically and clinically diagnosed at the Department of Urology, Shanghai Sixth People's Hospital of Shanghai Jiaotong University from 2010 to 2013. For the use of these clinical materials for research purposes, prior patient's consents and approval were collected, and the approvals by the Institutional Research Ethics Committee were obtained.

Isolation of fibroblasts from urethral scar tissues

A six-well plate was coated with a $0.1 \%$ gelatin solution and then incubated for $20 \mathrm{~min}$. The dissected tissue parts from urethral scar tissue or control normal urethral tissue were put in separated large petri dishes and a scalpel was used to cut pieces as small as possible. Hereafter, the pieces were carried over

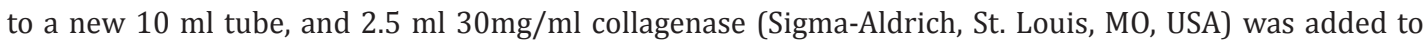

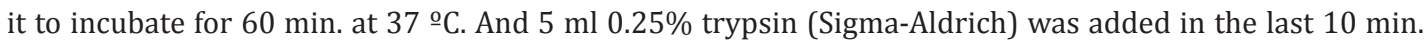
The tubes were centrifuged for $5 \mathrm{~min}$. at $300 \mathrm{~g}$. The gelatin was removed from the dish, and the volume was distributed equally over 2 coated wells and placed in the incubator for 2 days. Passaging of the cells 


\section{Cellular Physiology Cell Physiol Biochem 2015;35:2233-2243 \begin{tabular}{l|l|l}
\cline { 2 - 2 } DOI: 10.1159/000374028 & C 2015 S. Karger AG, Basel
\end{tabular} \begin{tabular}{l|l} 
and Biochemistry Published online: April 08, 2015 & www.karger.com/cpb
\end{tabular}

was done when the culture plate grown confluent. A small plane of $0.25 \%$ trypsin was added to the cells after removing the medium and placed in the incubator at $37^{\circ} \mathrm{o}$ for 10 minutes. Now the loosen cells were put in a tube. The culture plate was washed with PBS and added to the cells. After centrifugation for 5 minutes at 1000 RPM, cells where resuspended and seeded at 1:3 dilution on a new coated plate which surface is now approximately 3 times larger. New culture medium was added and the cells were placed in the incubator. The culture media was Dulbecco's modified Eagle's media (DMEM, Invitrogen, Carlsbad, CA, USA) supplemented with 15\% fetal bovine serum (Invitrogen). PD98059, LY294002 and IWP-2 were both purchased from Sigma-Aldrich.

\section{Transduction of human fibroblasts}

The coding sequence of TIMP-1 was amplified using human cDNA as a template, and cloned into pLVX-ZsGreen1-C1 vector (Clontech, Mountain View, CA, USA). Short hairpin interfering RNAs (shRNAs) targeting TIMP-1 used the published sequences [21]. The shRNA was also cloned into pLVX-ZsGreen1-C1 vector, with pLVX-ZsGreen1-C1 itself as the mock control. To generate TIMP-1 or shTIMP-1 lentiviral particles, NIH HEK293T cells were seeded in a $100 \mathrm{~mm}$ dish at 50,000 cells $/ \mathrm{cm}^{2}$ and co-transfected with $10 \mu \mathrm{g}$ of recombinant DNA plasmids and $5 \mu \mathrm{g}$ each of packaging plasmids (REV, pMDL and VSV-G) using Lipofectamine-2000 (Invitrogen). The supernatant containing lentiviral particles was collected 48 hours after transfection and filtered through a $0.45 \mu \mathrm{m}$ syringe filter. The fibroblasts were seeded in $100 \mathrm{~mm}$ plates at 15,000 cells $/ \mathrm{cm}^{2}$ one day prior to lentiviral infection. The lentiviral particles were added along with $10 \mu \mathrm{g} / \mathrm{ml}$ polybrene (Sigma-Aldrich) to the cell culture for 24 hours. Then the cells were washed twice with complete media and purified for the transduced cells, based on expression of GFP.

\section{Transwell migration assay}

The transwell migration assay was performed using a Fluorometric Cell Migration Assay kit with polycarbonate membrane inserts (5- $\mu \mathrm{m}$ pore size; Cell Biolabs, San Diego, CA, USA). Cells $\left(4 \times 10^{4}\right)$ were serum-starved overnight in DMEM prior to initiation of the experiment, and added to the upper chamber. Cells were then incubated at $37^{\circ} \mathrm{C}$ for 24 hours to allow cell migration through the membrane to the lower chamber. The cells inside the upper chamber were then removed with cotton swabs. Migratory and invasive cells on the lower membrane surface were fixed, stained with hematoxylin, and counted for 10 random 100X fields per well. Cell counts are expressed as the mean number of cells per field of view. Five independent experiments were performed and the data are presented as mean \pm standard deviation (SD).

\section{Scratch wound healing assay}

Scratch wound healing assay was performed as has been described previously [22]. Cells were seeded in 24-well plates at a density of $10^{4}$ cells/well in complete DMEM and cultured to confluence. The cell monolayer was serum starved overnight in DMEM prior to initiating of the experiment. Confluent cell monolayer were then scraped with a yellow pipette tip to generate scratch wounds and washed twice with media to remove cell debris. Cells were incubated at $37^{\circ} \mathrm{C}$ for 24 hours. Time lapse images were captured after 12 hours using a Nikon Eclipse TE2000-5 microscope. Images were captured from five randomly selected fields in each sample, and the wound areas are calculated by NIH ImageJ software.

\section{Cell proliferation assay}

For assay of cell proliferation, the cells were seeded into 96 well-plate at 4000 cells per well and subjected to a Cell Proliferation Kit (MTT, Roche, USA), according to the manufacturer's instruction.

\section{RNA extraction, reverse transcription and quantitative RT-PCR}

Total RNA was extracted from the cultured cells, or tissue, or patient specimens using Trizol (Invitrogen), according to the manufacturer's instruction. For mRNA analysis, complementary DNA (cDNA) was randomly primed from $2.0 \mu \mathrm{g}$ of total RNA using the Omniscript reverse transcription kit (Qiagen, Hilden, Germany). Quantitative Real-time PCR (RT-qPCR) was subsequently performed in duplicate with a 1:4 dilution of cDNA using the Quantitect SyBr green PCR system (Qiagen) on a Rotorgene 6000 series PCR machine. Data were collected and analyzed using the Rotorgene software accompanying the PCR machine. Relative expression levels were determined using the comparative quantification feature of the Rotorgene software. Levels of gene transcripts were normalized to $\alpha$-tubulin, and then compared to controls. 
Western blot and ELISA

Protein was extracted from the cultured cells or conditioned media by RIPA buffer (Sigma-Aldrich) for Western Blot. The supernatants were collected after centrifugation at $12000 \times \mathrm{g}$ at $4^{\circ} \mathrm{C}$ for $20 \mathrm{~min}$. Protein concentration was determined using BCA protein assay, and whole lysates were mixed with $4 \times$ SDS loading buffer (125 mmol/l Tris-HCl, 4\% SDS, 20\% glycerol, $100 \mathrm{mmol} / \mathrm{l}$ DTT, and $0.2 \%$ bromophenol blue) at a ratio of 1:3. Samples were heated at $100{ }^{\circ} \mathrm{C}$ for $5 \mathrm{~min}$ and were separated on SDS-polyacrylamide gels. The separated proteins were then transferred to a PVDF membrane. The membrane blots were first probed with a primary antibody. After incubation with horseradish peroxidase-conjugated second antibody, autoradiograms were prepared using the enhanced chemiluminescent system to visualize the protein antigen. The signals were recorded using X-ray film. Primary antibodies for Western Blot are anti-TIMP-1, anti- $\alpha$-SMA, anti-Collagen I and anti- $\alpha$-tubulin (all purchased from Cell Signaling, San Jose, CA, USA). Secondary antibody is HRP-conjugated anti-rabbit (Jackson Labs, Bar Harbor, ME, USA). Images shown in the figure were representative from 5 repeats. Densitometry of Western blots was quantified with NIH Image software. ELISA for TIMP-1 in the conditioned media was performed using a commercial ELISA kit (R\&D Systems, Minneapolis, MN, USA), according to the manufacturer's instruction.

\section{Statistical analysis}

All statistical analyses were carried out using the SPSS 19.0 statistical software package. All data were statistically analyzed using one-way ANOVA with a Bonferoni Correction. Bivariate correlation was calculated by Spearman's Rank Correlation Coefficients. All values are depicted as mean \pm standard deviation from 5 individuals and are considered significant if $p<0.05$. The figures were generated in Prism 6.0 (GraphPad Software Inc, USA).

\section{Results}

Correlated increases in TIMP-1 and $\alpha$-SMA levels in urethral scar tissues

In order to figure out whether TIMP-1 may induce the transformation of fibroblasts into myofibroblasts to promote EMT, we examined the transcript levels of TIMP-1 and $\alpha$-SMA, a marker for myofibroblasts and the levels of EMT in tissue, in the resected urethral scar tissue specimens (US), compared to the normal urethral tissues (NU) from the same patient. We also analyzed the correlation between TIMP- 1 and $\alpha$-SMA levels in individual patients. We detected significantly higher levels of TIMP-1 (about 8 fold increase, Fig. 1A), and significantly higher levels of $\alpha$-SMA (about 6 fold increase, Fig. 1A) in US, compared to NU. In addition, a strong correlation between TIMP- 1 and $\alpha$-SMA levels was detected (Fig.

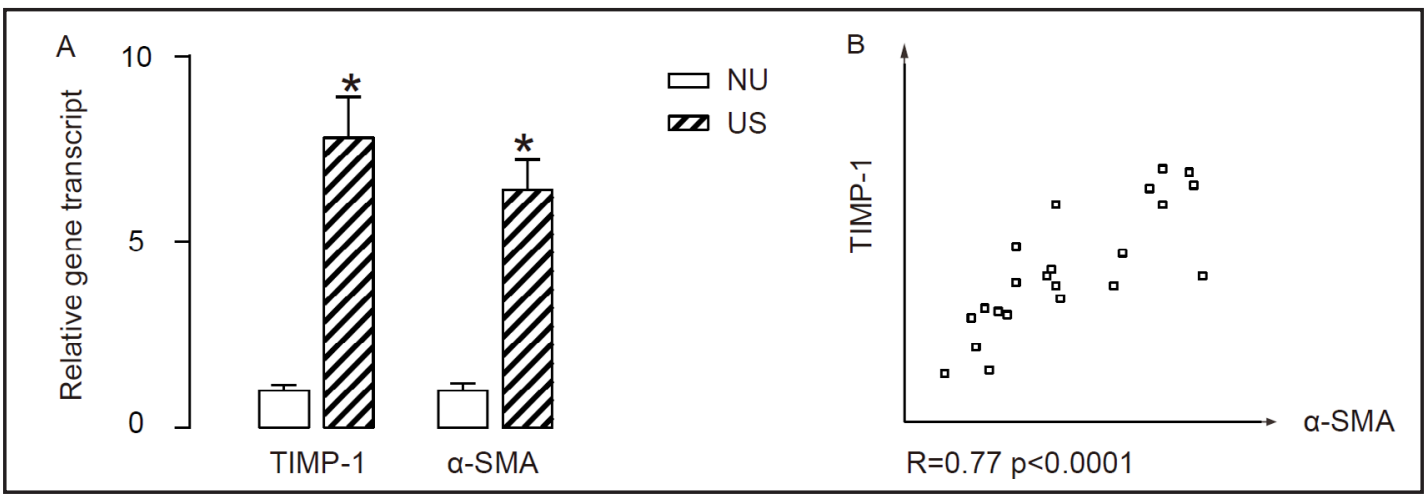

Fig. 1. Correlated increases in TIMP-1 and $\alpha$-SMA levels in urethral scar tissues. The transcript levels of TIMP- 1 and $\alpha$-SMA in the resected urethral scar tissue specimens (US) were compared to the normal urethral tissues (NU) from the same patient. (A) Significantly higher levels of TIMP-1 (about 8 fold increase) and $\alpha$-SMA (about 6 fold increase) were detected in US, compared to NU. (B) A strong correlation between TIMP-1 and $\alpha$-SMA levels was detected $(\mathrm{R}=0.77, \mathrm{p}<0.0001) .{ }^{*} \mathrm{p}<0.05 . \mathrm{n}=21$. Statistics: one-way ANOVA with a Bonferoni Correction. Bivariate correlation was calculated by Spearman's Rank Correlation Coefficients. 


\section{Cellular Physiology}
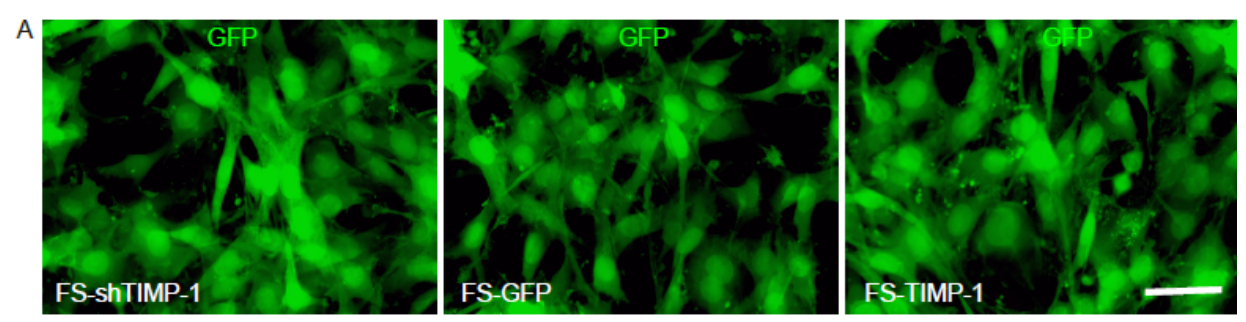

B
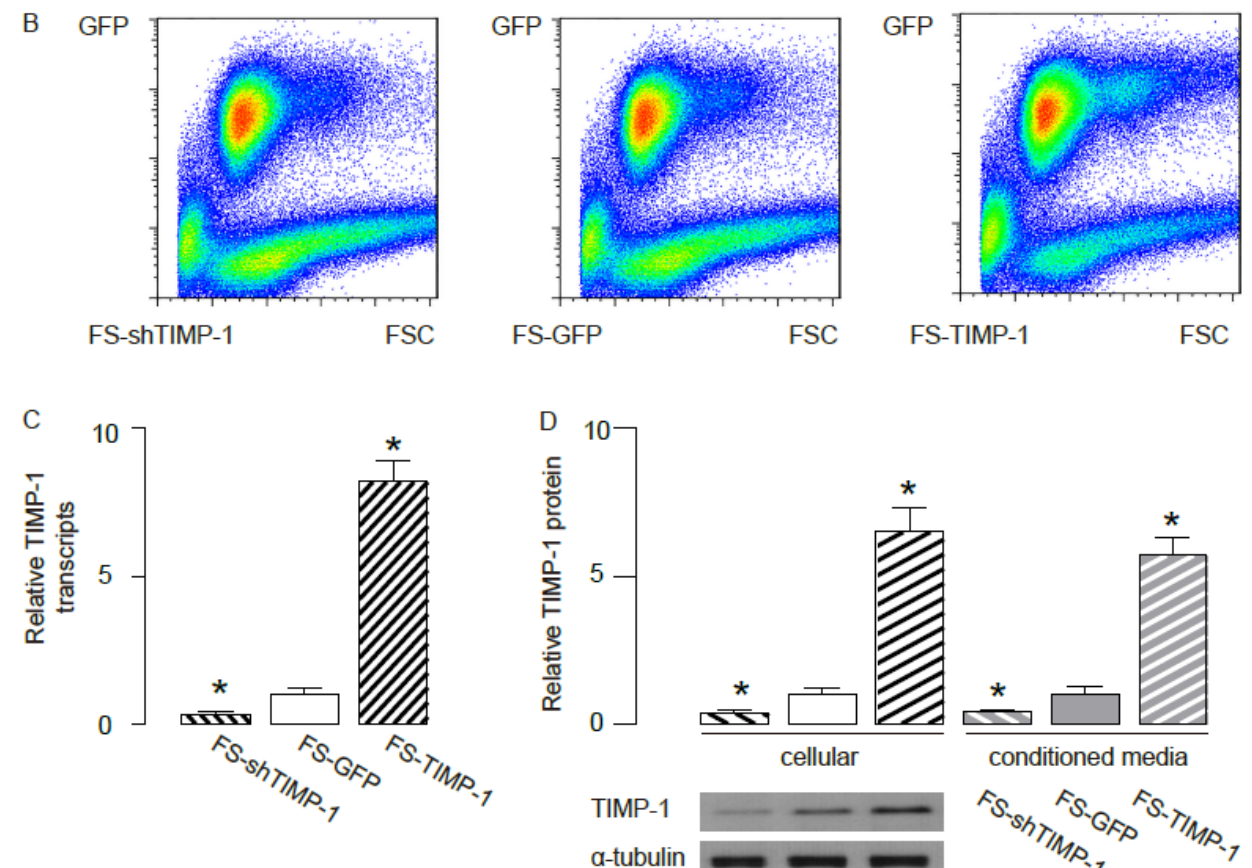

TIMP-1

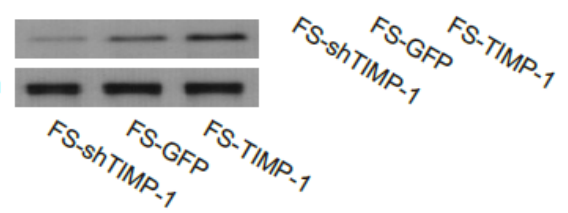

Fig. 2. Preparation of TIMP-1-modified human fibroblasts from urethral scar tissues. (A-B) Human fibroblasts (FS) were isolated from urethral scar tissues and transduced with either a TIMP-1 expressing lentivirus (FS-TIMP-1), or a lentivirus carrying shRNA for TIMP-1 (FS-shTIMP-1), or a control lentivirus (FS-GFP). All viruses contained GFP as a reporter, to allow transduced cells to be visualized in culture (A), and to be purified by flow cytometry (B). (C-D) The modifications of TIMP-1 levels in these cells were confirmed by RT-qPCR on TIMP-1 transcripts (C), by Western blot on cell extracts and by ELISA on conditioned media (D). FSC: forward scatter. ${ }^{*} \mathrm{p}<0.05 . \mathrm{N}=5$. Representative images are randomly selected from 5 repeats. Statistics: one-way ANOVA with a Bonferoni Correction. Scale bar is $20 \mu \mathrm{m}$.

1B, $r=0.77, p<0.0001$ ). These data suggest a causal link between TIMP- 1 and $\alpha$-SMA in the formation of urethral scar.

Preparation of Timp-1-modified human fibroblasts from urethral scar tissues

Then we isolated human fibroblasts (FS) from urethral scar tissues. To examine whether TIMP-1 directly regulates $\alpha$-SMA and other events of EMT, we transduced FS with either a TIMP-1 expressing lentivirus, or a lentivirus carrying small short hairpin interfering RNA for TIMP-1, or a control lentivirus. All viruses contained GFP as a reporter, to allow transduced cells to be visualized in culture (Fig. 2A), and to be purified by flow cytometry (Fig. 2B). The purified cells were termed as FS-TIMP-1, FS-GFP and FS-shTIMP-1, respectively. The modifications of TIMP-1 levels in these cells were confirmed by RT-qPCR (Fig. 2C), and by Western blot on the cell extracts (Fig. 2D), and by ELISA on the conditioned media (Fig. 2D). 


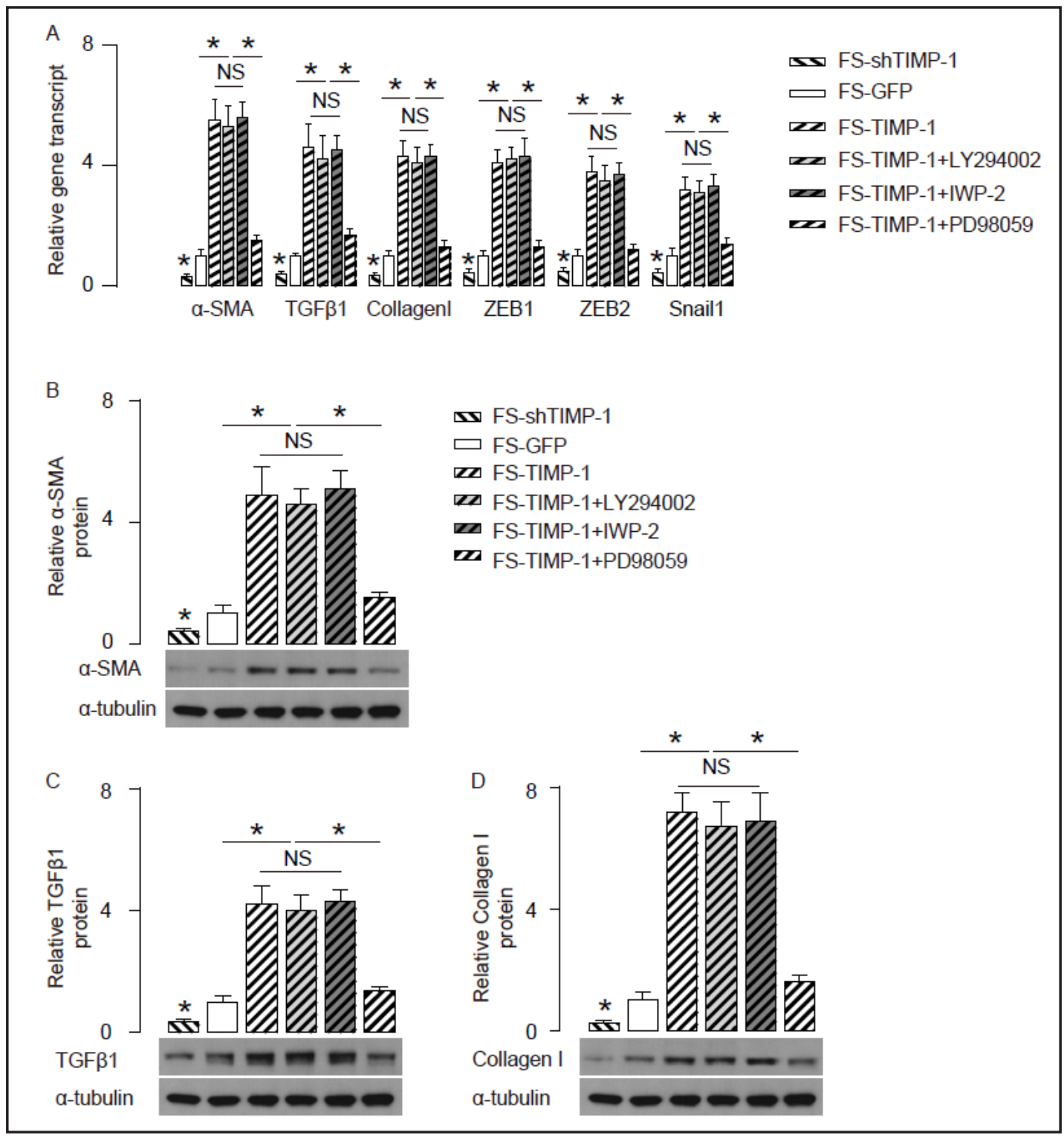

Fig. 3. TIMP-1 induced transformation of fibroblasts into myofibroblasts. (A) RT-qPCR for $\alpha$-SMA, TGF $\beta 1$, Collagen I, ZEB1, ZEB2 and Snail1 in Timp-1-modified fibroblasts (cell extracts). (B-D) Western blot on cell extracts for $\alpha$-SMA (B), TGF $\beta 1$ (C) and Collagen I (D) in TIMP-1-modified fibroblasts. LY294002 (20 $\mu \mathrm{mol} / \mathrm{l})$, IWP-2 $(1 \mu \mathrm{mol} / \mathrm{l})$, and PD98059 $(10 \mu \mathrm{mol} / \mathrm{l})$ were added to cell culture to inhibit respective signaling pathways. ${ }^{*} \mathrm{p}<0.05$. NS: non-significant. $\mathrm{N}=5$. Representative images are randomly selected from 5 repeats. Statistics: one-way ANOVA with a Bonferoni Correction.

TIMP-1 induced transformation of fibroblasts into myofibroblasts

We found that overexpression of TIMP-1 in FS significantly increased $\alpha$-SMA and TGF $\beta 1$ levels, while inhibition of TIMP-1 in FS significantly decreased $\alpha$-SMA and TGF $\beta 1$ levels, by RT-qPCR (Fig. 3A), and by Western blot (Fig. 3B-C). Since both $\alpha$-SMA and TGF $\beta 1$ are markers for myofibroblasts that trigger EMT, we then examined the levels of Collagen I, a key player in urethral scar formation, and the levels of some EMT-related genes. We found that overexpression of TIMP-1 in FS significantly increased Collagen I levels, while inhibition of TIMP-1 in FS significantly decreased Collagen I levels, by RT-qPCR (Fig. 3A), and by Western blot (Fig. 3D). Moreover, overexpression of TIMP-1 in FS also significantly increased EMTrelated genes ZEB1, ZEB2 and Snail1, while inhibition of TIMP-1 in FS significantly decreased 
Fig. 4. TIMP-1 increased fibroblast growth. Cell growth was examined in a MTT assay, and the values on O.D. at $570 \mathrm{~nm}$ were shown. LY294002 (20 $\mu \mathrm{mol} / \mathrm{l})$, IWP$2(1 \mu \mathrm{mol} / \mathrm{l})$, and PD98059 $(10 \mu \mathrm{mol} / \mathrm{l})$ were added to cell culture to inhibit respective signaling pathways. ${ }^{*} \mathrm{p}<0.05$. NS: non-significant. N=5. Statistics: one-way ANOVA with a Bonferoni Correction.

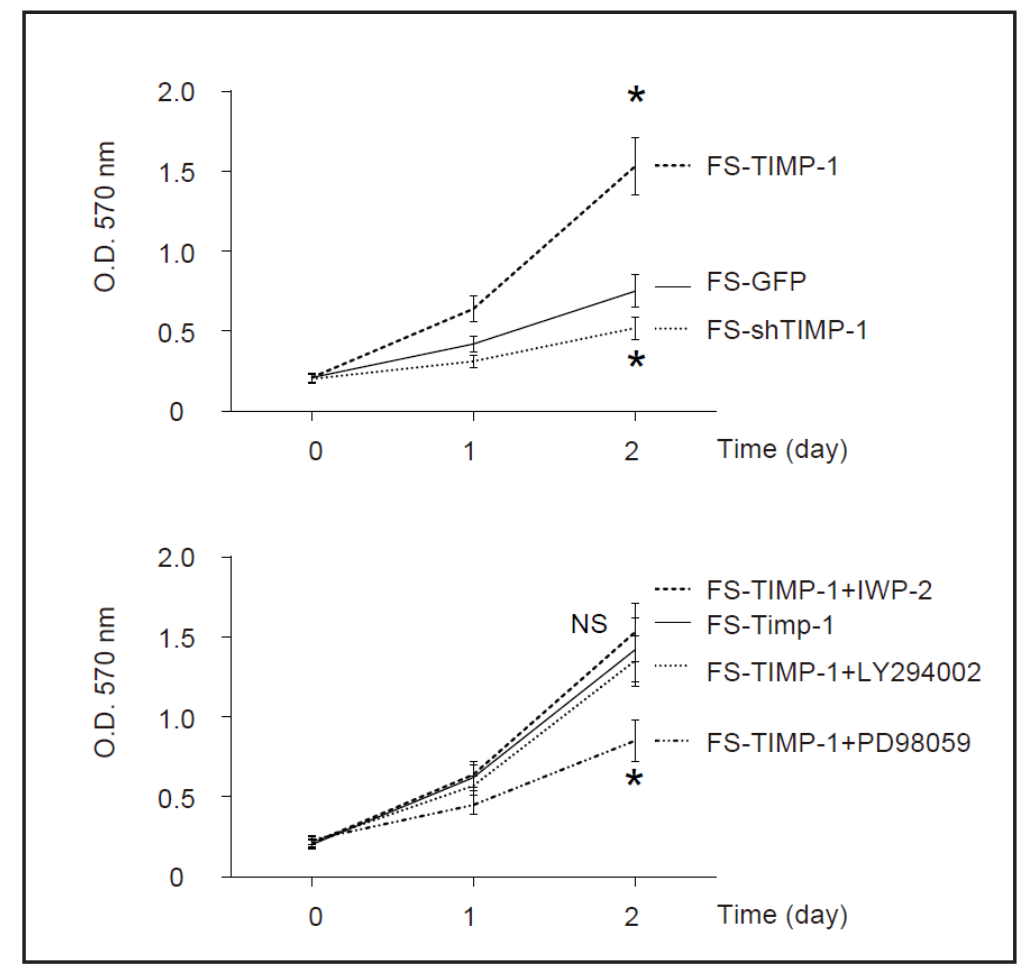

Fig. 5. TIMP-1 increased fibroblast invasiveness. (A-B) Overexpression of TIMP-1 in FS significantly increased cell migration and invasion, while inhibition of TIMP-1 in FS significantly decreased cell migration and invasion, in either a scratch wound healing assay (A), or a transwell migration assay (B). LY294002 (20 $\mu \mathrm{mol} / \mathrm{l})$, IWP$2(1 \mu \mathrm{mol} / \mathrm{l})$, and PD98059 $(10 \mu \mathrm{mol} / \mathrm{l})$ were added to cell culture to inhibit respective signaling pathways. ${ }^{*} \mathrm{p}<0.05$. NS: non-significant. N=5. Statistics: one-way ANOVA with a Bonferoni Correction.

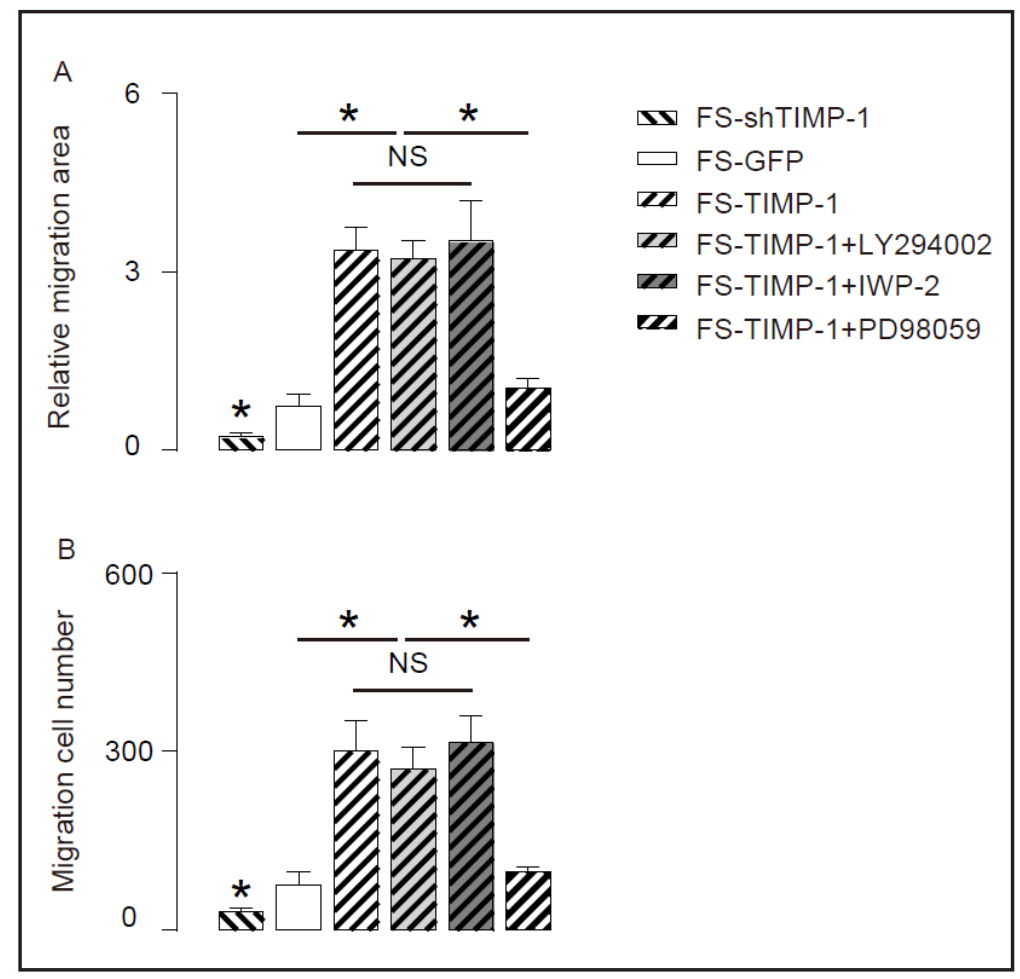

these genes (Fig. 3A). Together, these data suggest that TIMP-1 may induce transformation of fibroblasts into myofibroblasts to promote processes of EMT.

TIMP-1 increased fibroblast growth

Moreover, we found that overexpression of TIMP-1 in FS significantly increased cell growth, while inhibition of TIMP-1 in FS significantly decreased cell growth, in a MTT assay 


\section{Cellular Physiology Cell Physiol Biochem 2015;35:2233-2243

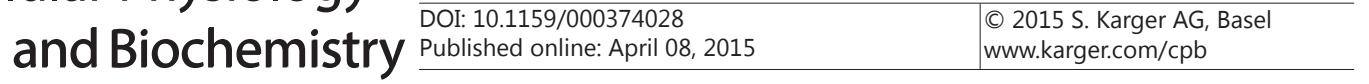

(Fig. 4, upper panel), suggesting that TIMP-1-induced transformation of fibroblasts may also promote fibroblast outgrowth.

\section{TIMP-1 increased fibroblast invasiveness}

In either a scratch wound healing assay (Fig. 5A), or a transwell migration assay (Fig. 5B), we found that overexpression of TIMP-1 in FS significantly increased cell migration and invasion, while inhibition of TIMP-1 in FS significantly decreased cell migration and invasion. These data suggest that TIMP-1-induced transformation of fibroblasts may also increase fibroblast invasiveness, which may eventually contribute to the formation of urethral scar.

TIMP-1 stimulated myofibroblast differentiation through ERK/MAPK signaling

Since PI3k/Akt, Wnt/ $\beta$-catenin and ERK/MAPK pathways may be activated by TIMP-

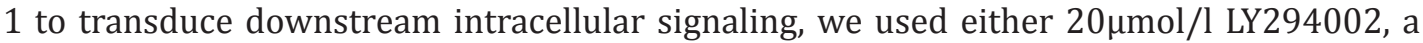
specific inhibitor to Akt, to inhibit PI3k/Akt signaling cascades in FS-TIMP-1 cells, or $1 \mu \mathrm{mol} / \mathrm{l}$ IWP-2, a specific inhibitor to $\beta$-catenin, to inhibit Wnt/ $\beta$-catenin signaling cascades in FSTIMP-1 cells, or $10 \mu \mathrm{mol} / \mathrm{l}$ PD98059, a specific inhibitor to ERK1/2, to inhibit ERK/MAPK signaling cascades in FS-TIMP-1 cells. We found that only application of PD98059 significantly abolished the TIMP-1-mediated induction of EMT-related factors (Fig. 3A-D), the increases in cell growth (Fig. 4, lower panel), and the increases in cell invasiveness (Fig. 5A-B). These data suggest that TIMP-1 stimulates myofibroblast differentiation through ERK/MAPK signaling.

\section{Discussion}

Urethral stricture is a disease of reduced lumen in a section of the urethra, often concomitant with decreased tissue flexibility due to severe fibrosis and collagen deposition, resulting in decreased urine flow or even retention [1-4]. Surgery is not sufficient to provide satisfactory treatments for urethral stricture [1-4]. Thus efficient therapeutic interventions, e.g. inhibition of fibrosis, or decrease of collagen deposition, or increase of collagenolysis, are highly needed [5-8].

Although TIMP-1 has been recently recognized to play a role in the urethral scar formation, it is mainly thought to inhibit collagenase activity [5-8, 23]. The effect of TIMP-1 on fibroblast transformation, however, has not been studied.

Here, we addressed to this important question. We found that the TIMP-1 directly regulated transformation of fibroblasts into myofibroblasts, evident from the examination on $\alpha$-SMA and TGF $\beta 1$ levels. $\alpha$-SMA is specific marker for myofibroblasts, and is not express by normal fibroblast [24-27]. The EMT is a process by which epithelial cells acquire a migratory, mesenchymal phenotype, as a result of its repression of E-cadherin [28-30]. Several signaling pathways (TGF $\beta$, FGF, EGF, HGF, Wnt/ $\beta$-catenin and Notch) regulate EMT, among which TGF $\beta$ receptor signaling triggered by TGF $\beta 1$ has been shown to be the most important one and extensively studied [31-42]. Loss of E-cadherin is considered to be a fundamental event in EMT [28-30]. Transcription factors Snail1, Slug1, ZEB1 and ZEB2 directly bind to E-cadherin promoter and repress its transcription [28-30]. Here, TIMP-1-induced TGF $\beta 1$ may bind to TGF $\beta$ receptor to activate downstream SMAD proteins, and then subsequently activate EMTrelated factors ZEB1, ZEB2 and Snail1, as has been previously reported [33, 43, 44]. Of note, we detected activation of all these factors by TIMP-1 overexpression, except for Snail2, which may be due to a cell/tissue-specific manner.

The exact causal relationship between fibroblast transformation and EMT was not further examined in the current study, since it is a well-established model [39, 45-51]. However, further proof of this regulatory axis is needed in follow-up studies. Together, our data highly suggest that in the current model, the EMT and fibrosis should be resulted from the transformation of fibroblasts into myofibroblasts. A set of loss-of-function and gain-offunction approaches, with the help of gene-knockout and gene-overexpression, should be taken to elucidate the exact signal transduction that regulates the whole process.

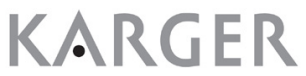




\section{Cellular Physiology Cell Physiol Biochem 2015;35:2233-2243

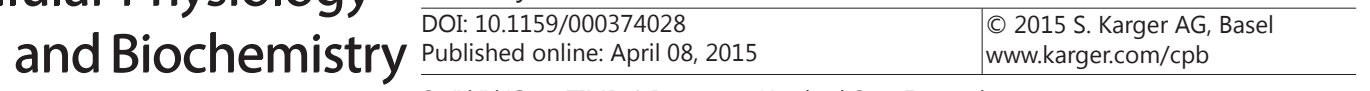

Our study illustrates a novel molecular mechanism that underlies the regulation of fibrosis and scar formation for urethral stricture, and suggests that besides affecting collagenase activity, TIMP-1 may also promote transformation of fibroblasts into myofibroblasts to enhance an EMT-mediated fibrosis and scar formation. These findings may provide novel insights upon the therapeutic approaches for patients with urethral stricture.

\section{Disclosure Statement}

The authors have declared that no competing interests exist.

\section{Reference}

1 Tritschler S, Roosen A, Fullhase C, Stief CG, Rubben H: Urethral stricture: Etiology, investigation and treatments. Dtsch Arztebl Int 2013;110:220-226.

2 Mangera A, Chapple C: Management of anterior urethral stricture: An evidence-based approach. Curr Opin Urol 2010;20:453-458.

3 Elliott SP, McAninch JW: The current role of urethrotomy in anterior urethral stricture disease. Curr Urol Rep 2006; 7:339-340.

$4 \quad$ Naude AM, Heyns CF: What is the place of internal urethrotomy in the treatment of urethral stricture disease? Nat Clin Prac Urol 2005;2:538-545.

5 Li C, Xu YM, Li HB: Preliminary experimental study of urethral reconstruction with tissue engineering and rna interference techniques. Asian J Androl 2013;15:430-433.

6 Palminteri E, Berdondini E, Maruccia S, Larocca L, Iannotta L, Franco G, Gentile V, Ceccarelli S, Marchese C: [preliminary resultson the use of autologous cell culture grafts of buccal mucosa in urethral repairs]. Urologia 2012;79:S111-115.

7 Ayyildiz A, Nuhoglu B, Gulerkaya B, Caydere M, Ustun H, Germiyanoglu C, Erol D: Effect of intraurethral mitomycin-c on healing and fibrosis in rats with experimentally induced urethral stricture. Int J Urol 2004;11:1122-1126.

8 Baskin LS, Constantinescu SC, Howard PS, McAninch JW, Ewalt DH, Duckett JW, Snyder HM, Macarak EJ: Biochemical characterization and quantitation of the collagenous components of urethral stricture tissue. J Urol 1993;150:642-647.

9 Liu G, Jiang C, Li D, Wang R, Wang W: Mirna-34a inhibits egfr-signaling-dependent mmp7 activation in gastric cancer. Tumour Biol 2014;35:9801-9806.

10 Wang X, Cao X: Regulation of metastasis of pediatric multiple myeloma by mmp13. Tumour Biol 2014;35:8715-8720.

11 Zhou X, Qi Y: Plgf inhibition impairs metastasis of larynx carcinoma through mmp3 downregulation. Tumour Biol 2014;35:9381-9386.

12 Wang F, Xiao W, Sun J, Han D, Zhu Y: Mirna-181c inhibits egfr-signaling-dependent mmp9 activation via suppressing akt phosphorylation in glioblastoma. Tumour Biol 2014;35:8653-8658.

13 Ding H, Zhu Y, Chu T, Wang S: Epidermal growth factor induces foxo1 nuclear exclusion to activate mmp7mediated metastasis of larynx carcinoma. Tumour Biol 2014;35:9987-9992.

14 Ries C: Cytokine functions of timp-1. Cell Mol Life Sci 2014;71:659-672.

15 Bodden MK, Windsor LJ, Caterina NC, Yermovsky A, Birkedal-Hansen B, Galazka G, Engler JA, BirkedalHansen H: Analysis of the timp-1/fib-cl complex. Ann N Y Acad Sci 1994;732:84-95.

16 Arthur MJ, Iredale JP: Hepatic lipocytes, timp-1 and liver fibrosis. J R Coll Physicians Lond 1994;28:200208.

17 Huang X, Wei DP, Yang YR: [detection of collagenase activity and tissue inhibitor of metalloproteinase-1 expression level in the urethral scar tissue]. Zhongguo Xiu Fu Chong Jian Wai Ke Za Zhi 2003;17:433-435.

18 Chen B, Wen Y, Zhang Z, Wang H, Warrington JA, Polan ML: Menstrual phase-dependent gene expression differences in periurethral vaginal tissue from women with stress incontinence. Am J Obstet Gynecol 2003;189:89-97. 


\section{Cellular Physiology Cell Physiol Biochem 2015;35:2233-2243 \begin{tabular}{l|l|l}
\hline DOI: 10.1159/000374028 & C 2015 S. Karger AG, Basel
\end{tabular} www.karger.com/cpb

19 Chen B, Wen Y, Wang H, Polan ML: Differences in estrogen modulation of tissue inhibitor of matrix metalloproteinase- 1 and matrix metalloproteinase-1 expression in cultured fibroblasts from continent and incontinent women. Am J Obstet Gynecol 2003;189:59-65.

20 Gobet R, Bleakley J, Cisek L, Kaefer M, Moses MA, Fernandez CA, Peters CA: Fetal partial urethral obstruction causes renal fibrosis and is associated with proteolytic imbalance. J Urol 1999;162:854-860.

21 Egea V, Zahler S, Rieth N, Neth P, Popp T, Kehe K, Jochum M, Ries C: Tissue inhibitor of metalloproteinase-1 (timp-1) regulates mesenchymal stem cells through let-7f microrna and wnt/beta-catenin signaling. Proc Natl Acad Sci U S A 2012;109:E309-316.

22 Liang CC, Park AY, Guan JL: In vitro scratch assay: A convenient and inexpensive method for analysis of cell migration in vitro. Nat Protoc 2007;2:329-333.

23 Jung YS, Liu XW, Chirco R, Warner RB, Fridman R, Kim HR: Timp-1 induces an emt-like phenotypic conversion in mdck cells independent of its mmp-inhibitory domain. PLoS One 2012;7:e38773.

24 Shen B, Liu X, Fan Y, Qiu J: Macrophages regulate renal fibrosis through modulating tgfbeta superfamily signaling. Inflammation 2014;37:2076-2084.

25 Wu TH, Li CH, Tang MJ, Liang JI, Chen CH, Yeh ML: Migration speed and directionality switch of normal epithelial cells after tgf-beta1-induced emt (temt) on micro-structured polydimethylsiloxane (pdms) substrates with variations in stiffness and topographic patterning. Cell Commun Adhes 2013;20:115-126.

26 Doerner AM, Zuraw BL: Tgf-beta1 induced epithelial to mesenchymal transition (emt) in human bronchial epithelial cells is enhanced by il-1beta but not abrogated by corticosteroids. Respir Res 2009;10:100.

27 Aresu L, Rastaldi MP, Scanziani E, Baily J, Radaelli E, Pregel P, Valenza F: Epithelial-mesenchymal transition (emt) of renal tubular cells in canine glomerulonephritis. Virchows Arch 2007;451:937-942.

28 Shang Y, Cai X, Fan D: Roles of epithelial-mesenchymal transition in cancer drug resistance. Curr Cancer Drug Targets 2013;13:915-929.

29 Kiesslich T, Pichler M, Neureiter D: Epigenetic control of epithelial-mesenchymal-transition in human cancer. Mol Clin Oncol 2013;1:3-11.

30 Meng F, Wu G: The rejuvenated scenario of epithelial-mesenchymal transition (emt) and cancer metastasis. Cancer Metastasis Rev 2012;31:455-467.

31 Leroy P, Mostov KE: Slug is required for cell survival during partial epithelial-mesenchymal transition of hgf-induced tubulogenesis. Mol Biol Cell 2007;18:1943-1952.

32 Lamorte L, Royal I, Naujokas M, Park M: Crk adapter proteins promote an epithelial-mesenchymallike transition and are required for hgf-mediated cell spreading and breakdown of epithelial adherens junctions. Mol Biol Cell 2002;13:1449-1461.

33 Xiao X, Gaffar I, Guo P, Wiersch J, Fischbach S, Peirish L, Song Z, El-Gohary Y, Prasadan K, Shiota C, Gittes GK: M2 macrophages promote beta-cell proliferation by up-regulation of smad7. Proc Natl Acad Sci U S A 2014;111:E1211-1220.

34 Gregory PA, Bracken CP, Smith E, Bert AG, Wright JA, Roslan S, Morris M, Wyatt L, Farshid G, Lim YY, Lindeman GJ, Shannon MF, Drew PA, Khew-Goodall Y, Goodall GJ: An autocrine tgf-beta/zeb/mir-200 signaling network regulates establishment and maintenance of epithelial-mesenchymal transition. Mol Biol Cell 2011;22:1686-1698.

35 Valcourt U, Kowanetz M, Niimi H, Heldin CH, Moustakas A: Tgf-beta and the smad signaling pathway support transcriptomic reprogramming during epithelial-mesenchymal cell transition. Mol Biol Cell 2005;16:1987-2002.

36 Muthusami S, Prabakaran DS, Yu JR, Park WY: Egf-induced expression of fused toes homolog (fts) facilitates epithelial-mesenchymal transition and promotes cell migration in me180 cervical cancer cells. Cancer Lett 2014;351:252-259.

37 Sakuma K, Aoki M, Kannagi R: Transcription factors c-myc and cdx2 mediate e-selectin ligand expression in colon cancer cells undergoing egf/bfgf-induced epithelial-mesenchymal transition. Proc Natl Acad Sci U S A 2012;109:7776-7781.

38 Shirakihara T, Horiguchi K, Miyazawa K, Ehata S, Shibata T, Morita I, Miyazono K, Saitoh M: Tgf-beta regulates isoform switching of fgf receptors and epithelial-mesenchymal transition. EMBO J 2011;30:783795.

39 Ramos C, Becerril C, Montano M, Garcia-De-Alba C, Ramirez R, Checa M, Pardo A, Selman M: Fgf-1 reverts epithelial-mesenchymal transition induced by tgf-\{beta\}1 through mapk/erk kinase pathway. Am J Physiol Lung Cell Mol Physiol 2010;299:L222-231. 


\section{Cellular Physiology Cell Physiol Biochem 2015;35:2233-2243 \begin{tabular}{ll|l} 
and Biochemistry & $\begin{array}{l}\text { DOI: 10.1159/000374028 } \\
\text { Published online: April 08, } 2015\end{array}$ & $\begin{array}{l}\text { O) 2015 S. Karger AG, Basel } \\
\text { www.karger.com/cpb }\end{array}$ \\
\cline { 2 - 3 } & Salli/Go: &
\end{tabular} \\ Sa/Li/Li/Guo: TIMP-1 Promotes Urethral Scar Formation}

40 Billottet C, Tuefferd M, Gentien D, Rapinat A, Thiery JP, Broet P, Jouanneau J: Modulation of several waves of gene expression during fgf- 1 induced epithelial-mesenchymal transition of carcinoma cells. J Cell Biochem 2008;104:826-839.

41 Yang N, Hui L, Wang Y, Yang H, Jiang X: Overexpression of sox2 promotes migration, invasion, and epithelial-mesenchymal transition through the wnt/beta-catenin pathway in laryngeal cancer hep-2 cells. Tumour Biol 2014;35:7965-7973.

42 Huang J, Xiao D, Li G, Ma J, Chen P, Yuan W, Hou F, Ge J, Zhong M, Tang Y, Xia X, Chen Z: Epha2 promotes epithelial-mesenchymal transition through the wnt/beta-catenin pathway in gastric cancer cells. Oncogene 2014;33:2737-2747.

43 Kang M, Choi S, Jeong SJ, Lee SA, Kwak TK, Kim H, Jung O, Lee MS, Ko Y, Ryu J, Choi YJ, Jeong D, Lee HJ, Ye SK, Kim SH, Lee JW: Cross-talk between tgfbeta1 and egfr signalling pathways induces tm4sf5 expression and epithelial-mesenchymal transition. Biochem J 2012;443:691-700.

44 Massague J: Tgfbeta signalling in context. Nat Rev Mol Cell Biol 2012;13:616-630.

45 Chen T, Nie H, Gao X, Yang J, Pu J, Chen Z, Cui X, Wang Y, Wang H, Jia G: Epithelial-mesenchymal transition involved in pulmonary fibrosis induced by multi-walled carbon nanotubes via tgf-beta/smad signaling pathway. Toxicol Lett 2014;226:150-162.

46 Sassoli C, Chellini F, Pini A, Tani A, Nistri S, Nosi D, Zecchi-Orlandini S, Bani D, Formigli L: Relaxin prevents cardiac fibroblast-myofibroblast transition via notch-1-mediated inhibition of tgf-beta/smad3 signaling. PLoS One 2013;8:e63896.

47 Gui T, Sun Y, Shimokado A, Muragaki Y: The roles of mitogen-activated protein kinase pathways in tgf-betainduced epithelial-mesenchymal transition. J Signal Transduct 2012;2012:289243.

48 Yoshimatsu Y, Watabe T: Roles of tgf-beta signals in endothelial-mesenchymal transition during cardiac fibrosis. Int J Inflamm 2011;2011:724080.

49 Schneider DJ, Wu M, Le TT, Cho SH, Brenner MB, Blackburn MR, Agarwal SK: Cadherin-11 contributes to pulmonary fibrosis: Potential role in tgf-beta production and epithelial to mesenchymal transition. FASEB J 2012;26:503-512.

50 Hills CE, Squires PE: The role of tgf-beta and epithelial-to mesenchymal transition in diabetic nephropathy. Cytokine Growth Factor Rev 2011;22:131-139.

51 Masszi A, Fan L, Rosivall L, McCulloch CA, Rotstein OD, Mucsi I, Kapus A: Integrity of cell-cell contacts is a critical regulator of tgf-beta 1-induced epithelial-to-myofibroblast transition: Role for beta-catenin. Am J Pathol 2004;165:1955-1967. 